\title{
Papillomavirus: Viral vectors in the gene therapy and new therapeutic targets
}

\section{Rachel Siqueira de Queiroz Simões* \& Ortrud Monika Barth}

\section{Laboratory of Morphologyand Viral Morphogenesis, Instituto Oswaldo Cruz, Fundação Oswaldo Cruz,} Avenida Brasil 4365, Manguinhos, 21040-900, Rio de Janeiro, RJ, Brazil.

\section{*Correspondence Info:}

Dr. Rachel Siqueira de Queiroz Simões

Laboratory of Morphology and Viral Morphogenesis,

Instituto Oswaldo Cruz, Fundação Oswaldo Cruz,

Avenida Brasil 4365, Manguinhos, 21040-900, Rio de Janeiro, RJ, Brazil.

E-mail: rachel.simoes@ioc.fiocruz.br; rachelsqsimoes@gmail.com

\begin{abstract}
Epitheliotropic and mucosotropic Papillomaviruses (PVs) constitute the Papillomaviridae family. There are 26 genera comprising levels of inter species genetic similarities by nucleotide sequence analysis of the L1 viral region, the generally most conserved region among papillomaviruses. There is an increasing consensus that the ideal vector for gene therapy should be completely based on chromosomal elements and behave as an independent functional unit after integration. The present paper is a short review about epidemiology of HPV infection, vaccines anti-HPV and tumors associated with HPV and gene therapy including biological vectors, stem cells, viral and non-viral vectors and chromosome-based vectors. Furthermore, new therapeutic targets and vectors applied in gene therapy of other viruses are some of the examples that have been successfully modified by recombinant DNA techniques. New biotechnologies in molecular biology have been applied in papillomavirus research and are still being investigated for the application in the gene therapy. RNA-sequencing (RNA-seq) for analysis of the transcriptome, multiply-primed rolling circle amplification (RCA) used to identify novel human papillomaviruses (HPV) and new DNA sequencing method based on real-time phyrophosphate are examples as new techniques.
\end{abstract}

Keywords:papillomavirus, viral and non-viral vectors, chromosomes, gene therapy

\section{Introduction}

Papillomaviruses are currently detected in a large variety of animals and have been shown highly species-specific. The family Papillomaviridae consists of 26 genera, among them 200 types isolated from humans; another ones were isolated from several species of animals, like birds and reptiles [1, 2]. New types of virus are continuously being discovered using a complete phylogenetic analysis of DNA genome sequences.

Several epidemiological studies point out to the involvement of papillomaviruses in the development of cancers. A major highlight occurs in cervical carcinogenesis. Studies of cervical cancer had broken through after the advent of molecular biology in the 70s [3-5].

The papillomavirus is a double-stranded circular DNA virus with approximately 7.900 nucleotide pairs, nonenveloped, presenting an icosahedral capsid of $55 \mathrm{~nm}$ diameter [6,7]. Detection IJBR (2015) 6 (10) of viral DNA sequences of the L1 gene, the stable and most conserved region of the viral genome, has been generally performed. Possible new types of PV isolated from animal species of the Brazilian fauna, presenting or not clinical signs of viral infection, were demonstrated by amplification of different sized fragments in blood samples according to the species investigated. Degenerate primers FAP59 (5' - TTA CWG TIG GIC AYC CWT ATT - 3') /FAP64 (5`CCW ATA TCW VHC ATI TCI CCA TC - 3'), designed by Forslund et al. (1999) for HPV DNA detection were applied [8]. These variations of amplicons generated were also found by Swedish researchers, demonstrating 12 new putative HPV types. The analysis of papillomavirus ORF L1 nucleotide sequences of animal species compared with the HPV sequences deposited in Gen Bank has been documented (Simões\& Barth, personal information), as well as the oncogenic role and 
expression of viral genes and the correlation of HPV with animal species [9].

Diagnostic assays capable of detecting highrisk types of HPV PCR have been used in the prevention of cervical cancer. The integrity of DNA extracted has generally been analyzed using PCR $\beta$ globin gene with PC04/GH20 primers (268bp) [10]. The consensus primers MY09/MY11 designed to amplify the segment of ORF L1 (450 bp) and nested PCR assay with GP5+/GP6+ primers (150bp) have been used [11].

This paper discuss about vaccines anti HPV, new therapeutic targets and vectors applied in gene therapy. Retroviruses, adenoviruses, adenoassociated virus (AAV), hybrid adenovirus-AAV, herpes simplex and vaccinia viruses are some of the examples that have been successfully modified by recombinant DNA techniques.

\section{Epidemiology of HPV infection}

In a recent study in Scotland, the prevalence of HPV in 20 to 21 years old women was of $32.2 \%$ in urine samples, $39.5 \%$ in swabs of self-collection and 49.4\% for cytology. Among the clinical specimens analyzed, the oncogenic types HPV-16/18 were detected in $23 \%$ of cytology samples, $16.6 \%$ collected on swabs and only $10 \%$ in urine samples [12].

In Italy, 566 women between 16 to 26 years of age were selected and diagnosed, using the normal cytology methodology, to detect the presence of HPV by amplification of ORF L1. Prevalence with predominance of the HPV-16 genotype was found in $18.2 \%$ of HPV positives, followed of the HPV-52 type [13].

A cross-sectional study in Greece with 3,177 women between 14 to 70 years of age, $12.9 \%$ of multiple infections of HPV with $27,4 \%$ prevalence of the high-risk types (HPV-16 and 51) was detected [14].

After the introduction of vaccination in health programs was detected the reduce of the prevalence of HPV-16/18 in sexually active young women in England [15].

It was possible to establish an association with vaginal $\mathrm{pH}$ and the presence of HPV infection in a populational study involving Costa Rica women aged between 18 and 97 years presenting changes in bacterial flora related to inflammation of the genital tract, as possible cofactors for the persistence of viral infection [16].

In Brazil, the HPV DNA (1.3\%) in the oral mucosa of asymptomatic men was detected. Machado et al. (2014) suggested that the practice of oral sex and a high number of partners may increase the risk of HPV infection [17].

In a case-control study in Brazil, cases of cancer in women under 30 years of age were not detected. Predictors for cervical cancer as early sexual activity, smoking, abortion and progression to cancer were related in different cohort populations indicating higher prevalence of HPV-16 [18]. Risk factors associated with single or multiple HPV infections were analyzed in a cross-sectional design, a community-based study with prevalence of $44.6 \%$ of HPV-positive women [10].

\section{Vaccines anti HPV and tumors associated with HPV}

Until the date, the best prevention strategy against cervical cancer, cervical intraepithelial neoplasia and genital warts has been the application of the vaccine. Since the implementation of the antiHPV vaccine in worldwide immunization programs, numerous studies have evaluated the impact of vaccination, and the prevention of thousands of new cases of cervical cancer in the next 50 to 100 years was estimated [12, 13, 19].

The economic impact of cost-effectiveness has also been documented in Estonia where the papillomavirus incidence rate is highly significant when compared with other Scandinavian countries [19]. It is estimated that in 100 years a reduction in the number of new cases of cervical cancer associated with HPV-16 and 18 types, and a decrease in the incidence of genital wart associated with HPV6 and 11 types of immunized 12 years old youth will occur [19].

A recombinant DNA technology has allowed the development of prophylactic vaccines for HPV. Early studies of vaccine development were conducted in Costa Rica during 2003 [19], but the first license in the United States of America occurred in 2006, the year that was also approved by the National Agency of Sanitary Surveillance in Brazil [21].

Currently, two vaccines are commercially available: a bivalent vaccine against HPV types 16 and 18 (GlaxoSmithKline Biologicals S.A) and the quadrivalent vaccine composed of antigen types 6 , 11, 16 and 18 (Sanofi Pasteurl Merck Sharp \&Dohme - MSD). Both vaccines are recombinant and presented Baculovirus and yeast as an expression system, respectively. The recombinant nonavalente vaccine was recently approved in the US for preventing cervical cancers, vulva, vagina and anal cancer caused by HPV types 16, 18, 31, 33, 45, 52 and 58 , and to prevent genital warts caused by HPV 
types 6 or 11. Tumors associated with HPV, such as tumors of the head and neck, and colorectal tumors, present the MLH1 and MSH2 genes as DNA repair genes [22].

Therapeutic vaccines have targeted the viral oncoproteins E6 and E7 due to its importance in oncogenesis and cell transformation. They act on the stimulation of cytotoxic $\mathrm{T}$ lymphocytes against specific epitopes. The therapeutic vaccination strategies include new therapeutic targets such as DNA-based vaccines, dendritic cell modified tumor cells, recombinant proteins, nanoparticles, synthetic peptides, viral vectors and bacterial and chimeric VLPs and immunotherapy, alone or associated with specific antiviral drugs.

Immunological memory is critical in protective immune response induced by vaccines. The protection afforded by the vaccine against HPV, which consists of virus-like particles (VLPs) of human papillomavirus (HPV), is mediated by the presence of neutralizing antibodies detected in the serum. The use of chimeric antigens offers the possibility of inducing not only humoral as well as a cell-mediated response. DNA vaccines are usually produced by amplifying the gene of interest into plasmids grown in bacteria, purified by conventional methods and are being tested. The production of a therapeutic virus should be similar to a pharmaceutical product as the normalization rules Good Manufacturing Practices (GMP) which involves clinical trials [23].

\section{HPV gene therapy}

Gene therapy involves diagnostic, treat and cure of diseases at a molecular level. Vectors are molecular tools used to transfer genes from one organism to another. Gene therapy involves the treatment at the DNA level of chromosome. There are two main types of vectors: viral and non-viral vectors.

Gene therapy has a great potential as a new therapeutic modality. The transfer of genes, viral vectors designs and applications of new therapies are considerable advances in biotechnology. Non-viral vectors and hybrid vectors and other technologies are being explored. Currently used vectors in human gene therapy suffer from a number of limitations with respect to safety and reproducibility [24].

There are various methods for introduction of genes into mammalian cells, facilitated by using chemical, physical and biological tools. Briefly, chemical methods may include DNA-calcium phosphate, DNA-DEAE dextran, DNA-lipide (liposomes not integrate into the genome of the host cell), DNA-protein and HCAs (artificial chromosomes). On the other hand, there are physical methods with high transfection rates such as direct microinjection, electroporation, high pressure plasmid injection and DNA ballistic injection.

The key point of human gene therapy clinical trials is the production of a therapeutic vector. The new proposal of gene therapy must be demonstrated by safety and effectiveness through the use of animal models, toxicology and biodistribution studies [22]. The clinical trials database are maintained at Wiley reports for clinical trials by disease such as cancer, cardiovascular disorders, infectious diseases, neurological disorders and others [25].

Only in the late 1990, two gene therapy trials were approved in the United States after failures in trials in the early 70s and 80s [26]. Non therapeutic protocols basically involve the administration of a vector for studying the immune effects in normal volunteers [24]. There are still some limitations in the field of genetics. The first flaw in molecular biology was related to two cases of arginase deficiency syndrome treated by using in vivo gene therapy wild-type Shope papillomavirus. The second attempt was with gene therapy for Bthalassemia in two patients using marrow cells treated with a B-globin-containing plasmid [24].

The another record was the case of a 18 years old man presenting ornithine transcarbamylase deficiency (OTCD) obtained from the transfer of a gene vector. OTCD is a systemic inflammatory response syndrome which the most common inherited disorder of the urea cycle. There are two genes that deserve to be discussed regarding the failure of gene therapy, which resulted in the death of the patient who was participating in a gene therapy trial [26].

In a therapeutic trial after almost three years of gene therapy, lymphoblastic leukemia occurred in two young patients. They developed lymphoproliferative disorder as a direct result of retroviral gene transfer to hematopoietic stem cells. Both clones from patients showed integration of the retrovirus vector in proximity to the promoter LM02 proto-oncogene that leads to an increased transcription and expression.

\subsection{Biological vectors}

The biological vectors used in gene therapy are: retroviridae family mainly gammaretroviruses and lentiviruses, for as example the Moloney-murine leukemia virus (Mo-MLV) and chimeric Moloney- 
Human lentiviral (prototype HIV-1) vector. Adenoviruses, adeno-associated virus (AAV), chimeric adenovirus-AAV and vaccinia virus are also other types of biological vectors. There are a number of additional viral vectors based on Epstein-barr virus, herpes simplex virus type 1 (HSV-1), simian virus 40 , hepatitis virus and papillomavirus, which are still being studied for application in clinical gene therapy [25, 27, 28].

Several viruses have been used as biological vectors to introduce of genes into mammalian cells using several physical methods: direct microinjection, electroporation, injection of plasmid and DNA ballistic injection. Construction of viral vectors has been accomplished by transfer techniques, recombination and gene expression, and have been widely used in screening clinical trials for gene therapy, since the technology for gene transfer occurs through the large capacity in which viruses have transferred part of their genome into target cells [23].

Furthermore, human adenovirus is the most commonly used in treatment of cystic fibrosis and cancer. Some studies are in clinical phase development level 1 and level 2. Basically, for gene therapy using an adenovirus vector, the vector binds to the cell membrane, in sequence the vector is packaged into vesicle, this vesicle break down releasing vector and protein is synthesized by cell using new gene.

The adeno-associated virus serotypes 2 and 5 (AAV 2 and AAV5) a potential vector for gene transfer due to its high power of infecting a wide range of cell lines. AAV have recently been used in the treatment of neurodegenerative processes for example Parkinson's and Alzheimer's diseases. The favored vectors applied in Parkinson`s disease (PD) are the adeno-associated viruses and the Lentiviruses (LV) using different molecular pathways [29]. There are very potential alternative gene therapy interventions for example with Parkin mutations using animal models, mutations in autosomic dominant gene or also MicroRNAs (miRNA) facilitate RNA-induced silencing complex (RISC) silencing of complementary mRNA [28].

Moreover, CD34 cells translated with the retrovirus vector using multiple ribozymes are indicated for the treatment of Non-Hodgkin 's Lymphoma and AIDS. There are other viruses such as Epstein-Barr virus, simian virus 40, papillomavirus, non-human lentiviruses and hepatitis viruses in which its properties for gene therapy are still being investigated [27].

\subsection{Stem cells}

The advancement of stem cell research provides tools to model diseases, test new drugs and develop effective therapies for use in regenerative medicine and cell therapy. The mapping of the stem cells can generate biomedical implications with prospects for production in vitro of pluripotent stem cells induced (iPS). These pluripotent stem cells are reprogrammed from somatic cells using retroviral vectors containing many genes. In the near future, the keratinocyte reprogramming will be possible in tissue engineering laboratories as creating new models for the study of tumors associated with HPV.

\subsection{Viral and Non-viral vectors}

The recombinant viral vectors are the most powerful vehicles for gene transfer. However the host immune response, the difficulty of standardization and mass production are still an obstacle for clinical use. In addition, to the viral packaging system and processes of purification and concentration of viral vector titles require long stages of processing. Considerable progress is expected in future prospects of the methods of gene transfer in vivo and ex vivo for use in the treatment of human diseases [28]. Viral vectors have provided efficient methods for in vivo gene delivery for a variety of therapeutic purposes. Viral vectors can activate antigen-presenting cells (APC) important for the induction of innate as well as adaptive immune responses [24].

Viral vectors include retrovirus, adenovirus, adeno-associated viruses, herpes simplex viruses, liposomes and DNA. Viruses are commonly used as vectors because of the complexity of structures and life cycle closely linked to the host cell. However, even with these advantageous characteristics, many viruses are pathogenic and deserve caution in use. Some types of viral vectors can be modified to achieve specific cell types in the body and can be genetically modified to prevent them from replicating and destroy the target cell. Therefore, it is extremely important to separate only the viral properties that must be maintained for the experiment. In this case, the most important is to retain the ability of the virus has to give his information to the cells where it is expressed and persists. Non-viral vectors have the advantage of low immunogenicity coupled with ample capacity for therapeutic DNA, however, are less efficient than viral vectors [30].

\subsection{Chromosome-based vectors}

In addition to viral and non-viral vectors there is a group of vectors called chromosome-based vectors. It is an increasing consensus that an ideal 
vector for gene therapy should be completely based on chromosomal elements and behaves as an independent functional unit after integration. A number of chromosomal elements, such as transposons, genetic insulators, enhancers, locus control regions, boundary elements, and scaffoldattachment or matrix-attachment regions, all of which are involved in the hierarchic regulation of mammalian gene expression and replication, have been used to design vectors that present artificial domains when integrating into the cell genome [24]. Oncolytic viruses for cancer therapy have been investigated also. An additional study with different adenovirus serotypes is to be used for the development of novel vaccine strategies [24]. Currently, several experimental models for vaccination have been developed using viral vectors inserting a DNA molecule that expresses the genes of interest. When compared with immunogenicity, the viral vectors are more immunogenic than DNA plasmids.

\section{HPV molecular screening}

Gene therapy clinical trials have exploited viral vectors as vehicles for clinical applications in particular on the molecular properties [25]. Molecular screening test strategies used degenerate primers for amplification by PCR to be able to identify not only viral types previously described, but also to detect possible new virus subtypes in human and animal species free clinical lesions [31, 32, 33, 34]. Many techniques in molecular biology have recently been employed in the detection of viruses. The HPV assay by hybrid capture has demonstrated high clinical sensitivity as in situ hybridization, polymerase chain reaction (PCR), nested PCR, multiplex PCR and restriction fragment length polymorphism (RFLP), sequencing and new DNA sequencing method based on real-time phyrophosphate. There are some tools used in biotechnology as fluorescence in situ hybridization (FISH) is a molecular cytogenetic technique used in chromosomal abnormalities studies. New biotechnologies in molecular biology have been applied in research papillomavirus for example RNA-Sequencing (RNA-seq) technique that allows the analysis of the transcriptome of genomes with high resolving power, monitoring of cell expression, and allows quantifying the transcript levels using the Illumina platform sequencing being a useful tool for gene mapping and identification of transcribed regions and multiply-primed rolling circle amplification (RCA) has been used to identify novel human papillomaviruses (HPV). Molecular and biological properties of papillomavirus are still being investigated for the application in the gene therapy.

\section{References}

[1] De Villiers E-M, Fauquet, C, Broker, T.R. Bernard H, ZurHausen, H. Minireview Classification of papillomaviruses. Virology 2004; 324:17- 27.

[2] Bernard H.U, Burk R.D, Chen Z, Van Doorslaer K, ZurHausen H, De Villiers E.M. Classification of Papilomaviruses (PVs) based on $189 \mathrm{PV}$ types and proposal of taxonomic amendments. Virology 2010; 401(1):70-79.

[3] ZurHausen H. Papillomaviruses genital cancer: synergism between two virus infection and initiating events? Lancet: 1982; 1370-2.

[4] ZurHausen H. Papillomaviruses as carcinomaviruses. AdvVirolOncol. 1989; 8:1-26.

[5] ZurHausen H. Papillomaviruses in human cancers. Molecular Carcinogenesis. 1998; 1:14750 .

[6] Howley, P.M. Papillomaviruses and their replication. In BN Field, DM Knipe, 1995.

[7] Shah, KV. Howley, PM. Papillomaviruses. In BN Field, DM Knipe (eds). Field's Virology, $3^{\text {rd }}$ ed., Raven Press, New York, p. 980-998, 1995.

[8] Forslund, O; Antonsson, A; Nordin, P; Stenquist, B; Hansson, B.G. A broad range of human papillomavirus types detected with a general PCR method suitable for analysis of cutaneous tumours and normal skin. Journal of General Virology, 1999; 80: 2437-2443.

[9] Marins, R.S.Q.S. Filogenia do papilomavírus e sua correlação com papilomavírus humano (human papillomavirus - hpv) e animal - revisão de literatura. PUBVET, Londrina, 2008; 1 (7).

[10] FigueiredoAlves, R.R., Turchi, M.D., Santos, L.E., Guimaraes, E.M.B., Garcia, M.M.D., Seixas, M.S.C., Villa, L.L., Costa, M.C., Moreira, M.A.R., Alves, M.F.C. Prevalence, genotype profile and risk factors for multiple human papillomavirus cervical infection in unimmunized female adolescents in Goiania, Brazil: a community-based study. BMC Public Health, 2013; 13:1041.

[11]Qu, W., Jiang, G., Cruz, Y., Chang, C.J., Ho, G.Y.F., Klein, R.S., Burk, R.D. PCR detection of human papillomavirus: comparison between MY09/MY11 and GP5+/GP6+ primer system. Journal of clinical microbiology, 1997; 13041310.

[12] Kavanagh, K., Sinka, K., Cuschieri, K., Love, J., Potts, A., Pollock, K.G, Cubie, H., Donaghy, M., 
Roberston, C. Estimation of HPV prevalence in Young women in Scotland; monitoring of furure vaccine impact. BioMed Central Infectious Diseases, 2013; 13:519.

[13] Panatto, D., Amicizia, D., Tanzi, E., Bianchi, S., Frati, E.R., Zotti, C.M., Lai, P.L., Bechini, A., Rossi, S., Gasparini, R. Prevalence of human papillomavirus in young Italian women with normal cytology: how should we adapt the national vaccination policy?.BioMed Central Infectious Diseases2013; 13:575.

[14] Argyri, E., Papaspyridakos, S., Tsimplaki, E., Michala, L., Myriokefalitaki, E., Papassideri, I., Daskalopoulou, D., Tsiaoussi, I., Magiakos, G., Panotopoulou, E. A cross sectional study of HPV type prevalence according to age and cytology. BMC Infectious Diseases, 2013, 13:53

[15] Mesher, D., Soldan, K., Howell-Jones, R., Panwar, K., Manyenga, P., Jit, M., Beddows, S., Gill, O.N. Reduction in HPV 16/18 prevalence in sexually active young women following the introduction of HPV immunization in England. Vaccine, 2014; 32: 26-32.

[16] Clarke, M.A., Rodriguez, A.C., Gage, J.C., Herrero, R., Hildesheim, A., Wacholder, S., Burk, R., Schiffman, M. A large, populationbased study of age-related associations between vaginal $\mathrm{pH}$ and human papillomavirus infection. BioMed Central Infectious Diseases 2012; 12:33.

[17] Machado, A.P., Almeida, F.G., Bonin, C.M., Prata, T.T.M., Ávilla, L.S., Padovani, A.M.T.F., Fernandes, C.E.S., Tozetti, I.A. Presence of high oncogenic human papillomavirus in the oral mucosa of asymptomatic men. The Brazilian Journal of Infectious Diseases, 2014; 18 (3): 266-270.

[18] Pereira, C.R.N., Rosa, M.L.G., Vasconcelos, G.A.L.B.M., Faria, P.C.P., Cavalcanti, S.M.B., Oliveira, L.H.S. Human papillomavirus prevalence and predictors for cervical cancer among high-risk women from Rio de Janeiro, Brazil. International Journal Gynecology Cancer2007; 17: 651-660.

[19] UusKula, A., Muursepp, A., Kawai, K., Raag, M., Jurisson, M., Pillsbury, M. The epidemiological and economic impact of a quadrivalent human papillomavirus (HPV) vaccine in Estonia. BioMed Central Infectious Diseases 2013; 13:304.

[20] Teixeira JC. Indicações do uso de vacina antiHPV. UrologiaEssencial, 2011; 1(3):36-41.

[21] Bricks, L.F. Vacina HPV: nova perspectiva na prevenção de câncer. Pediatria, 2007; 29(2):154156.
[22] Molina, A.L., Tobo, P.R. Uso das técnicas de biologia molecular para diagnóstico. Einstein: 2(2):139-142.

[23] Costanzi-strauss, E., Strauss, B.E. Terapia Gênica do Câncer. BiotecnologiaCiência $e$ Desenvolvimento, 2002; 28: 26-28,

[24] Raper, S.E. Gene Therapy.The good, the bad and the ugly. Surgery, 2005; 137 (5):487-492.

[25] Giacca, M., Zacchigna, S. Virus-mediated gene delivery for human gene therapy. Journal of controlled release, 2012; 161: 377-388.

[26] Scollay, R. Gene therapy: a brief overview of the past, present and future. Annals New York Academy of Sciences2001: 26-30.

[27] Kay, M.A., Liu, D., Hoogerbrugges, P.M. Gene Therapy. Proceedings of the National Academy of Sciences, 1997; 94: 12744-12746.

[28]Dani, S.U. Terapia Gênica. Biotecnologia, Ciência e Desenvolvimento, 2012: 28-33.

[29] Berry, A.L., Foltynie, T. Gene therapy: a viable therapeutic strategy for Parkinson`s disease? Journal of Neurological, 2011; 258 (2): 179$188,$.

[30] Mohr L, Geissler M. Gene therapy: new developments. Praxis, 2002; 2227-35.

[31] Antonsson A., McMillan, N.A.J. Papillomavirus in healthy skin of Australian animals. Journal of General Virology, 2006; 87: 3195-3200.

[32] Ogawa, T., Tomita, Y., Okada, M., Shinozaki, K., Kubonoya, H., Kaiho, I., Shirasawa, H. Broad-spectrum detection of papillomaviruses in bovine teat papillomas and healthy teat skin. Journal of General Virology2004; 85:21912197.

[33] Mello, W.A. Investigação de papilomavírus em primatas não-humanos do Novo Mundo: ocorrência e caracterização molecular. Tese de Doutorado, Biologia de Agentes Infecciosos e Parasitários, Universidade Federal do Pará UFP, Belém, 2005: 115.

[34] Marins, R.S.Q.S. Biodiversidade do papilomavírus: análise de sequências de nucleotídeos do gene L1 depositadas no genbank. ConferênciaSul-Americana, Teresópolis, Rio de Janeiro, 2012. 